\title{
$\mathrm{PH} 105$
}

\section{El patrimonio industrial marítimo y el Camino de Santiago se vinculan como base para el diseño de un futuro itinerario cultural}

El verano pasado se llevaba a cabo, de la mano de dos equipos multidisciplinares constituidos por jóvenes, el trabajo de campo base del proyecto experimental denominado Recaladas No Camiño, que tiene como fin último la creación de la primera senda del patrimonio industrial a lo largo del Camino de Santiago, ligado al patrimonio marítimo y pesquero de las Rías Baixas. Se trató de una expedición de siete días, integrada por estudiantes o recién titulados, cuyos resultados se presentaban como propuestas de itinerarios en una conferencia en el Museo del Mar de Galicia a finales de septiembre.

María Isabel Puerto Fernández | Grupo de investigación HUM805, Universidad de Granada

URL de la contribución <http://www.iaph.es/revistaph/index.php/revistaph/article/view/5029>

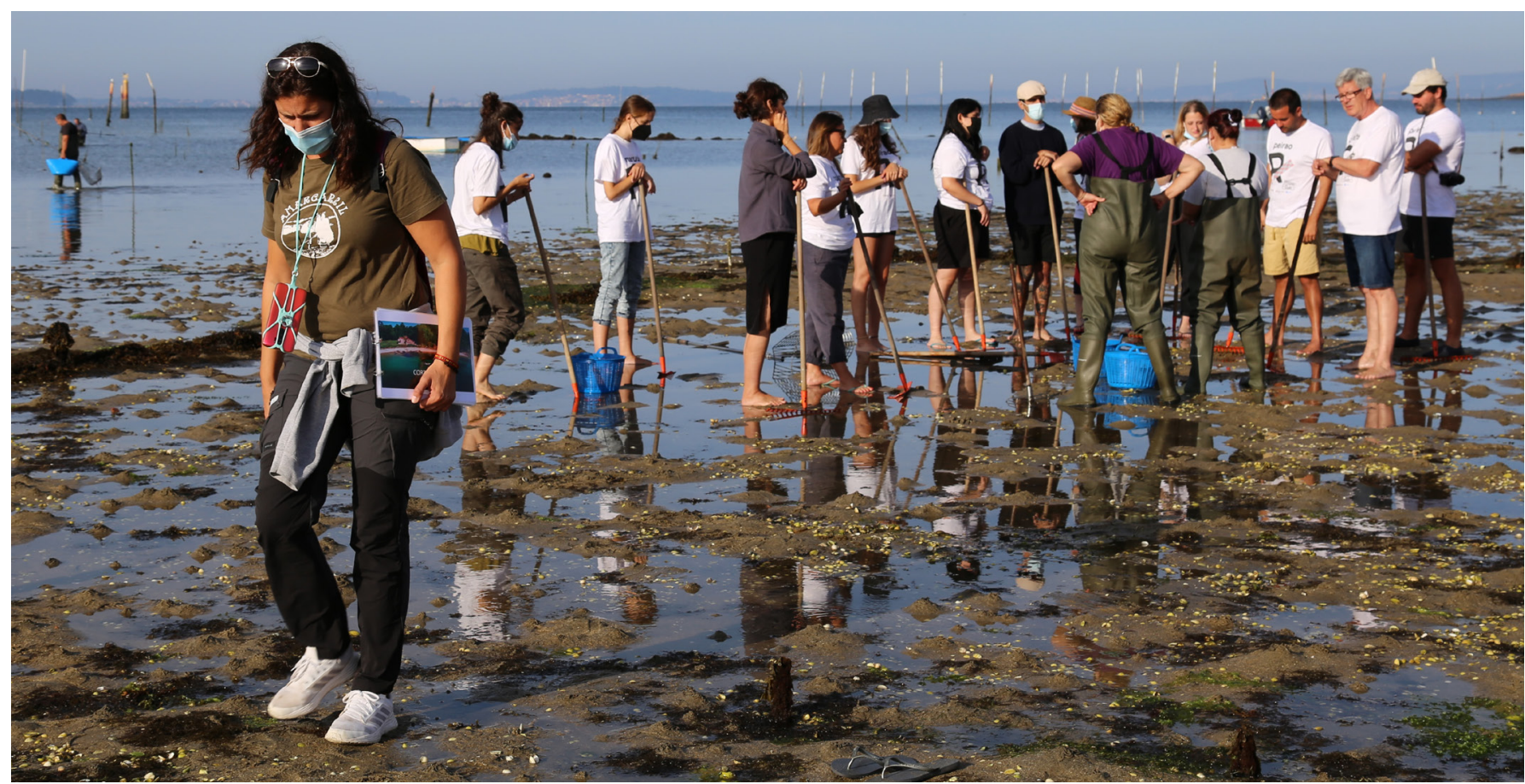

Jornada de expedición con las mariscadoras de Carril | foto Fundamar

Recaladas No Camiño es un proyecto experimental, impulsado por Fundamar (Fundación para la pesca y el marisqueo) y patrocinado por Xacobeo 21.22 y Xunta de Galicia, que nació con la idea de poner en valor el patrimonio industrial, pesquero y marítimo de las Rías Baixas a través de la creación de una senda vinculada al Camino de Santiago portugués, concretamente en las rías de Vigo y de Arousa. El equipo científico y organizador de Recaladas No Camiño ha estado formado por personas que pertenecen a entidades del ámbito académico y profesional, vinculados a la valorización de patrimonio y a los objetivos del proyecto: Xoán 
Carmona (Universidad de Santiago), Julián Sobrino (Universidad de Sevilla), Manuel Lara (presidente de Buxa, Asociación Gallega de Patrimonio Industrial), Iria Sobrino (arquitecta y experta en patrimonio) y María Caldeiro, gerente de Fundamar.

El trabajo de campo ha sido llevado a cabo, con el acompañamiento en todo momento del citado comité organizador y científico de este proyecto, por dos equipos multidisciplinares integrados por 11 jóvenes menores de treinta años, procedentes de distintos lugares de España, seleccionados bajo los criterios de igualdad de género e inclusión. Los participantes de los equipos, bautizados con los nombres Peirao y Marusía, realizaron trabajo de campo en puntos clave de los dos nodos de interés (Ría de Vigo y Ría de Arousa) durante siete días, entre el 30 de agosto y el 5 de septiembre de 2021.

El objetivo de la expedición ha sido crear una propuesta, por cada uno de los dos equipos participantes, para un futuro itinerario en torno al patrimonio industrial de esta zona, centrado en el patrimonio marítimo y pesquero, tanto material como inmaterial, y vincularlo al Camino de Santiago portugués como forma de atractivo tanto para el visitante como para el local. Las dos propuestas finales de itinerarios se han realizado bajo la supervisión del citado comité científico y fueron presentadas en el Museo Do Mar de Galicia el día 29 de septiembre de $2021^{1}$. En paralelo, se realizó una exposición, en este mismo museo, entre los días 29 de septiembre y 24 de octubre, con una instalación en la que se mostraron los resultados obtenidos tras la expedición de Recaladas No Camiño.

\section{Itinerarios conectados al acervo del mar}

Durante el desarrollo del proyecto Recaladas No Camiño se han puesto sobre la mesa los problemas que atañan a la sociedad de las Rías Baixas, quienes ven cómo los bienes intangibles del patrimonio marítimo y pesquero están en peligro paulatino de desaparición; y cómo los bienes tangibles conformados en torno a las actividades ligadas al mar corren el mismo riesgo si no se actúa para su protección y conservación. Para ello es primordial que las formas y modos de vida de la sociedad, la memoria oral y las artes tradicionales del mar se divulguen y se transmitan, tanto entre las nuevas generaciones locales

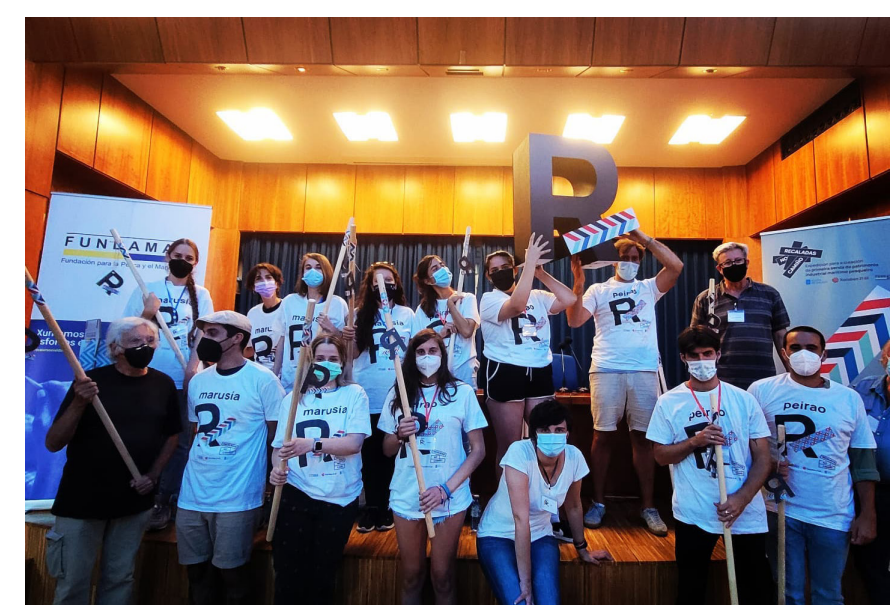

Integrantes del proyecto Recaladas No Camiño | foto Fundamar

como los visitantes, bajo un modelo turístico que respete la identidad de la sociedad de las Rías Baixas.

Partiendo de esta premisa, se construye la idea de crear un itinerario utilizando el marco de oportunidades ligadas al Camino de Santiago como gancho fundamental. Reutilizar los recursos y espacios del patrimonio industrial y darles un nuevo uso y enfoque sin perder su valor esencial que es la actividad marinera y pesquera: el elemento como comunicante de lo que ha existido. Para ello se han incluido como propuestas la creación de talleres, catas gastronómicas, ferias, residencias artísticas, conciertos musicales y otras actividades culturales en estos espacios para fomentar la divulgación de las tradiciones y que a su vez sean un aliciente tanto para el público foráneo como para el público local, especialmente juvenil. Muy importante este segundo grupo de usuarios para que exista una conservación real del acervo y sea perdurable en el tiempo.

Los valores que se han desarrollado en el proyecto para la puesta en marcha del futuro itinerario han sido: la sostenibilidad, con un turismo responsable y respetuoso con el medio ambiente y sus recursos; la accesibilidad a todo tipo de usuarios; feminismo como valor principal para conseguir igualdad entre todas las personas, especialmente en las actividades marítimas y pesqueras.

El patrimonio es algo intrínseco a los grupos sociales y además la sociedad forma parte y se vale de éste. Es evi- 
dente el lazo de unión entre sociedad y patrimonio por lo que es fundamental que se establezcan buenas relaciones y conexiones para que haya un reconocimiento y un impulso de preservación de todo el patrimonio cultural. Comprender los usos y formas del patrimonio marítimo y pesquero material -el caso del patrimonio industrial por ejemplo- e inmaterial, entendiendo que el edificio no es solamente lo importante sino también el hecho patrimonial en sí. Estos factores configuran paisajes patrimoniales capaces de narrar sobre los grupos sociales, de sus tradiciones y de sus oficios. Que el caminante forme parte de este paisaje.

Para su conservación es ideal la metodología aplicada desde el consenso del grupo social. La acción participativa de la sociedad debe de aplicarse mediante la identidad local, el reconocimiento cultural litoral, la educación en patrimonio y la perspectiva intergeneracional para su correcta transmisión. El fin está en sí mismo, el uso social en continuidad.

En definitiva lo que se pretende con Recaladas No Camiño es revalorizar el patrimonio industrial marítimo y pesquero, su salvaguarda y poner en dinámica todos los recursos patrimoniales de índole material e inmaterial.

El proyecto Recaladas No Camiño ya se ha desarrollado y queda cerrado tras alcanzar sus objetivos iniciales: las propuestas de itinerarios patrimoniales realizadas por los equipos Marusía y Peirao. Llevar a la realidad estas propuestas dependerá fundamentalmente de los recursos económicos y del aval de diferentes instituciones.

\section{NOTAS}

1. https://www.youtube.com/watch?v=lb4UeNJxhMc\&$\mathrm{t}=2493$ s\&ab_channel=RecaladasNoCami\%C3\%B1o

\section{BIBLIOGRAFÍA}

- Calo Lourido, F. (2019) Vida e traballo no mar dos galegos. Santiago de Compostela: Museo do Pobo Galego

- Carmona Badía, X. (2010) Lo material y lo inmaterial en el Patrimonio Industrial de Galicia: algunas notas sobre su situación y características. En: Patrimonio industrial y paisaje. Gijón: Cicees, pp. 533-541

- Carmona Badía, X. (coord.) (2011) Las familias de la conserva. El sector de las conservas de pescados a través de sus sagas familiares. Pontevedra: Deputación de Pontevedra / Anfaco-cecopesca

- Lara Coria, M. (2016) Pegadas da industrialización en Galicia. A Enseada de San Simón. Santiago de Compostela: Ensenada de Ézaro Ediciones

- Sobrino Fagilde, I. (2008) Arquitectura industrial en Vigo. En: Arquitectura industrial en la provincia de Pontevedra. Vigo. Disponible en: https://noncommon.files.wordpress. com/2012/04/00-a-indyarq_1-393_low.pdf [Consulta: 14/12/2021]

- Sobrino Simal, J. (2016) Industria, memoria y olvido: La cultura del trabajo como periferia patrimonial. En: Layuno, A. y Pérez, J. (ed.) Patrimonio industrial en las periferias urbanas. Alcalá de Henares: Ayuntamiento de Alcalá de Henares, pp. 31-46

- Sobrino Simal, J. (2019) Pensando el patrimonio industrial. Los retos del siglo XXI. Periférica: Revista para el análisis de la cultura $y$ el territorio, n. ${ }^{\circ} 20$, pp. 88-99 